\title{
Parental Perceptions on ECD Provisioning In Mdantsane District, Eastern Cape
}

\author{
Jenny Shumba \\ Symphorosa Rembe \\ Goje Pumla \\ University of Fort Hare, Private Bag X1314, Alice 5700 \\ jennymshumba@gmail.com
}

\section{Doi:10.5901/mjss.2014.v5n9p457}

\begin{abstract}
This paper sought to explore parental perception on ECD provisioning at early childhood centres. The key questions asked were: What are the perceptions of parents on the role of ECD centres? What are the perceptions of parents regarding participation in ECDC Activities? Four parents, two from each of the two selected centres were purposively sampled. All the four respondents were female. Data was collected through interviews and document analysis. The results revealed that parents perceived the role of ECD centres as: for the provision of food, security from perpetrators of rape, play activities that render children exhausted by the time they go home, intellectual and spiritual development and as a stepping stone into formal schooling. Parental participation was found to be very minimal. Parents perceived that by getting involved they would be disturbing the smooth running of the centres. It can be concluded that parents were neither conversant of the roles of ECD centres and roles they need to play in ECD centres for the benefit of learners. The study recommended among other things parental education on ECD provisioning for both parents and educators.
\end{abstract}

Keywords: Early Childhood Development, Early Childhood Development centres, parental participation

\section{Introduction}

Early childhood development (ECD) refers to the early childhood period and the wide range of set developmental and integrated services for children and families (Britto, Yoshikawa \& Boller, 2011). These services include provision of ECD resources such as ECD centres; international and national policies; training of personnel and other stakeholders; the curriculum specifications and funding (Department of Education, 1996). The age of ECD cohort is context bound. For example, in the United States of America it is 0-8 years (Britto et al, 2011; Deiner, 2010) and in South Africa it is 0-9 yrs (National Integrated Plan for Development in South Africa 2005- 2010: 2005). A multi- sectoral approach to ECD provisioning has been adopted by various governments due to the complex nature of ECD (Britto,et al, 2011; Viviers, Biersteker \& Moruane, 2013). ECD programmes are cross- cutting as they involve departments such as health, education and social development. (Bridman, 2011; Britto, et al, 2011; Vargas-Baron \& Schipper, 2012). Various stakeholders work together towards the achievement of ECD goals. Parents are some of the key stakeholders.

The ECD centre is the first formal agent of socialisation (Kibera \& Kimokoti, 2007). Its role is to lay a foundation for a child's holistic and integrated education that meets cognitive, social, moral, spiritual, emotional, physical and developmental needs (Githinji \& Kanga, 2011; Landry, 2008). Early childhood development can reduce educational and social wastage (Mwaura, 2009 in Githinji \& Kanga, 2011) and forms the foundation of all future developments, such as, linguistic, socio-emotional and cognitive (Storbeck \& Moodley, 2011). Early childhood centres therefore service current and future goals of children's development.

Brofenbrenner $(1979,1983)$ posits that for ECD programmes to be effective and have lasting impact, parents and communities need to be involved. Researches support the notion that parental involvement in children's education has positive outcomes as the parents gain knowledge about school activities and would render valuable guidance to their children (Holloway, Yamamoto, Suzuki and Mindnich, 2008). The parents in most circumstances are the primary caregivers and the central figures in the "heart of children's universe" (Farquhar, 2003 in Mukuna and Indoshi, 2012). Hence, their involvement in early childhood education serves as a motivator that bridges the gap between two contexts, the home and school (Nokali, Bachman, Votrba-Drzal, 2010).

Parent participation ranges from being recipients of services through to being instigators and controllers of 
programmes from passive to very active roles (Evans, 2006). The participation of parents in their children's education is highlighted in the South African Children's Act (2006), wherein it is stated as one of the four main principals. The act states that first and foremost it is a parental responsibility to meet the needs of the child and thus advocates for partnerships between parents and other carers in the best interest of the child and to the success of the ECD programmes. Parent participation includes the quality and frequency of communication with teachers as well as participation in school functions and activities (Nokali, et al, 2010). Mukuna \& Indoshi (2012) bring in another version of parental participation whereby it is organised into two, school- centred parent involvement and home- centred parent involvement. School- centred parent involvement includes activities such as participation in classroom, social and service events, attending PTA meetings and attending and participating in school board meetings. Home- centred parent involvement is where parents do activities with their children such as assisting children with homework, providing them with proper nutrition and healthcare.

Determinants of parental participation can be classified into three categories: contextual, programmatic and personal. Contextual determinants include the nature of parenting in that time frame, locale and social milieu. The local culture, traditions language, value systems and norms are part of the context. Programmatic determinants embrace the stage and nature of the programme, access to resources and beliefs about the value of parental participation. Those of a personal nature include parents not being a homogeneous group, parental knowledge, skills or experience base and other daily life factors (Evans, 2006). Holloway et al (2008) aver that parents' cognition about their role has been identified as a major determinant of their willingness to participate. Key cognitions identified are parents' aspirations for their children's future, parents' self-efficacy in rearing and educating their children and their perceptions of the school. Hence, the determinants can help in the achievement of either positive or negative outcomes. In line with this, WebsterStratton (1991) suggests lack of confidence, poverty, divorce, illness or job stress as contributory to parental nonparticipation in their children's education. However, the author (Webster- Stratton, 1991) proposes that both teachers and parents be trained in family involvement in order to avert conflicts and to encourage good practice.

Research in Japan indicated that parents selfishly neglect their children's schooling and their development whilst indulging themselves in their "hedonistic desire for leisure or employment" (Holloway et al, 2008). This has negative ramifications. For instance, Japanese government officials and media cited neglectful parents as the cause of indiscipline such as bullying, absenteeism and disruptive behaviour in the schools (Okano \& Tsuchiya, 1999 in Holloway et al, 2008).

Literature reveals the following as some of the barriers to meaningful parent participation in education: time, low self esteem, hours of employment, social deprivation and poverty and feelings of inadequacy (Wall, 2011). Parents' participation can also be influenced by their different needs, skills, fears, vulnerabilities, their attitudes, personalities, experience, employment patterns, socio-economic pressures, religious affiliations and cultural practices (Brown, 1998). Some get involved when offered sensitive support and understanding. The intimidating professionalism of the educators can also hinder parents from participating. Theories discussed below

\subsection{Theoretical Framework}

The current study was guided by Bronfenbrenner's ecological systems theory and Epstein's theory of parental involvement.

Bronfenbrenner's ecological systems theory is based on the premise that throughout life one encounters different environments which affect their existence. These according to Bronfenbrenner are the microsystem, mesosystem, exosystem, macrosystem and chronosystem. The microsystem is the environment that one interacts with at the most basic level, such as, family, friends, teachers and neighbours. As one interacts within this environment one co-constructs the experiences with the other players, the person shapes and is equally shaped by the others (Bronfenbrenner, 1993). The mesosystem involves relationships between the microsystems in a one's life. It is a system of microsystems (Bronfenbrenner, 1994) For example, one's home experience may be related to one's school experience. It is at this level that the Epstein theory of parental involvement operates. In the exosystem environment there is a link between the contexts where the person is actively involved with one where there is no direct involvement. For instance, the ECD child's exosystem could be the child's father's workplace. On the other hand, the macrosystem encompasses the culture of an individual. The cultural contexts involve the belief systems, race, ethnicity and material resources. Parental participation in ECD activities can be influenced by a parent's belief system or material resources at his or her disposal. The chronosystem involves change, transitions and shifts in one's life. For example, divorce in the family may affect the child's school attendance and subsequently performance.

Epstein's theory of parental involvement is an offshoot of Brenfenbrenner's theory, at the mesosystem level, as it deals with the two microsystems the parent and the school with the child at the centre of the puzzle. It involves 3 
"spheres of influence" on children's development (Epstein, 1995, 2001). These are school, family and community. Educational development is enhanced when the three environments/spheres work collaboratively toward shared goals. In this context, the ECD centres should aim to create an overlap between itself (school), home and community. Epstein's typology of parent involvement includes parenting, communication to and from school, volunteers, learning activities at home, decision-making and collaborating with the community. This is in agreement with Lander's assertion that parents have four roles in child's learning development, namely decision-making, volunteering, planning and partnering. This study focuses on how parents perceive the role of ECD centres to be and how they perceive their participation in ECD provisioning to be. The four cases discussed below each has a story to tell on the role of ECD centres and parental participation.

\section{Research Methodology}

1. Research design: A case study design was employed in this study in this qualitative research. Maree (2007) avers that a case study is a systematic inquiry into an event or a set of related events which aims to describe and explain the phenomenon of interest. The phenomenon of interest in this study is two pronged: parents' perception of the role of ECD centres and their participation in ECD centres.

2. Case selection: Purposive sampling was used to select the information rich cases (Bryman. 2012; Ritchie, 2003; Stake, 2000; Yin, 2011). Multiple case studies were selected. Two centres were selected and these constituted the case. As The Free Library (2006) posits, the case study method was selected due to the fact that it can be used to efficiently probe beneath the surface of a situation and provide a rich context for understanding phenomena under investigation, in this case parent participation in ECD provisioning. Four parents (two from each centre) with children in the centres were selected and interviewed. Two of the "parents" were grandparents of the children at the centres. These lived with the children as their real parents were away in towns. The researchers considered these suitable participants as they brought in a new dimension to the whole matrix of ECD provisioning.

3. Instrumentation: The main instrument used for data collection was the semi-structured interview so as to capture the participants' views, beliefs and perceptions on ECD provisioning. The researchers used the qualitative interviews in order to see the phenomenon through the eyes of the respondents (Maree, 2007). The researchers managed to create a conducive atmosphere for free discussion with participants during data collection. Document analysis was also used. Bowen (2009: 27) suggests that document analysis is a "systematic procedure for reviewing or evaluating documents". The researchers systematically reviewed the attendance registers and the minutes of meetings previously held at the centres to check on the participation levels of the parents.

4. Data analysis: Qualitative data analysis transforms textual data into findings (Patton, 2002). In this study the researchers organised the data into themes in tandem with the research questions. The themes were inductively obtained from the text data and some verbatim accounts of the respondents were included in the analysis to assist the researchers to produce the rounded picture of ECD provisioning and parental participation.

5. Measures to ensure trustworthiness: Babbie and Mouton (2005) contend that the basic issue of trustworthiness is on how the enquirer can persuade his/her audiences that the findings are worthy taking account of. To ensure trustworthiness the researchers did a member check where together with participants they shared the information and its interpretation and confirmed if what is written is the correct version of their responses.

6. Ethical issues: Qualitative data researchers are never far from ethical issues and dilemmas (Schutt, 2012). The sensitive nature of the study raised ethical issues that needed careful consideration during the research process. For instance the researchers discovered that some of the "parents" were grandparents when data collection was in progress and had to make prompt decisions to continue. The researchers also had to contend with the pain the participants felt due to the desertion of their children (Mothers to the ECD centre learners). The participants were assured of the ethical considerations such as privacy, anonymity and confidentiality and were made to sign consent forms stipulating the researchers' and their roles in the study.

\section{Results}

The study unravelled that some "parents" in the sampled centres were maternal grandparents and that the real mothers 
had gone to cities in search for jobs. What is striking about the situation is that the mothers took the children's Child Support Grant cards with them to towns leaving the grandparents to fend for the children with their meagre pensions. This might reveal the selfish streak of the mothers who have very little regard for their parents and offsprings.

Parents perceived that the role of ECD centres was for their children to get food. For instance two parents intoned that;
We send them for food. Ah ...it is because here they eat three meals and I cannot afford some of the food they eat here. P2
We send them here because towards the end of the month we do not have enough food so here they are always provided with food and care. P1

The reasons above can be viewed from two sides as it shows both selfish and altruistic tendencies of the parents. Selfish reasons are implied in that the parent thinks only of the material benefit of ECD centres and ignores the other unquantifiable benefits that are intellectual, psycho-social or physical. Altruism is also evident in that the parent might have seen the genuine need for food and realised that the ECD centre provided the solution. The lack of food in the houses and the dependency on social grants may be an indication that the children in the locale of the centres hail from poor backgrounds.

The study also revealed that parents send their children to ECD so that they get time to do other chores. Some of the reasons proffered are contained in the verbatim accounts below:

\title{
My husband is sick and I have many grandchildren so I send them here so that I can be able to attend to their sick grandfather, in other words and I can have space.P1
}

According to P1, she sent her grandchildren to school in order for her to look after her ailing husband without disturbance from the children. As she states, she needs "space".

P2 also claimed to have sent her child to the ECD centre "for play so that they become tired and sleep when they get home". P2 The reason for sending the child seems mean. She wants the child to get exhausted and not infringe on the parent's time and space. Like P1 she also needs space. One wonders what the ECD child's allocated space is.

Another parent, P4's reason for sending her child to ECD implied coercion. She sent the child to school for motives derived from a clandestine source, that is, ECD policy. She stated:

Because it is mandatory for the child to go to for ECD before the child is enrolled for grade 1. If your child does not attend these ECDCs then the child will not be accepted or registered at the normal school. It is a pre-requisite of the school that is what we have been told by the principal of that ...school. P4

From P4's statement, the researchers felt there is a gap in the parents' understanding of ECD policy issues. P4 begrudgingly seemed to imply that the principal just created his/her policies as gatekeeping means and to deny children access to the normal school.

Safety was given as another motive of sending children to ECD centres. P1 proffered the following:

\begin{abstract}
Because it is a safe place. There are high rape rates in our area that is why we send them here. When the child is not well they take the child to the clinic and report later. and they won't rape them here. I never heard that ever since they opened this place.P1
\end{abstract}

Parents also sent children to ECD centres for intellectual and spiritual development as highlighted by the respondent cited below: It broadens their minds, we now see the difference in the way they think. They learn many things from the centres and they learn to pray before eating.

The layman's language "broadens their minds" could mean that there was some intellectual development noted by the parent after the child had had some interaction with the ECD environment. Realisation of spiritual development was evidenced in claims that at ECD centres children learnt to pray before consuming food.

Parental participation and support was shown in the following captions:

\footnotetext{
I show her how to hold a pen, if I am not tired or tell him to tell his parents when I am back.P1

I can see he is not holding the crayon in a proper way, although I am as uneducated as I am, I can see if it is improper and report to her parent when she is back during the weekend.P2

I show her how to smear, she is very curious and I even taught her how to wash her underwear. I teach her house chores but she insists and wants to carry on with chores.P3
} 
The first two respondents (P1 and P2) indicated that the parents' help on school issues went as far as psychomotor skills training- proper handling of pencils and crayons. These two were hindered in their endeavours to participate by tiredness as well as illiteracy, respectively. P3 on the other hand is mainly concerned with social development in the form of training the child to do household chores.

All parents in the sample suggested that they did not fully participate in ECD centre activities. The data above reflects that the parents send their children to ECD centres then stand aloof and watch what happens, metaphorically, "with folded" hands. Reasons for this may need further investigation. below:

From the findings it was revealed that parents did not participate fully in ECD activities due to reasons proffered

Illiteracy. Some parents suggested that they could not interfere with the ECD centre's activities as they were illiterate and would spoil the running of the centre. Some claimed to be illiterate and not aware that they needed to participate. The following responses were given to justify their non-participation:

\author{
... as I am illiterate I was not aware that I must have a part here. I do not attend their meetings. P1 \\ Oma... (Referring to the centre manager using her clan name) are supposed to take care of everything here. We do not \\ want to spoil this. We are far from education. P2 \\ I was not aware that I must assist, I do not have a problem I will wait for the centre manager to delegate me. P3 \\ I do not want to come to meetings because it is for Ma... and Oma... because they are educated and they built these \\ shacks (Centre classrooms). P4
}

Apart from illiteracy, the parents exuded lack of confidence. Parents such as P3 intimated that they would wait for duties to be delegated to them because they may be seen as too forward in a project that was started by the centre manager. This may portray that parents have low self -esteem because of their handcap; illiteracy. Parents need to be tutored in order to improve their self -efficacy. Bandura (1997:3) claims that self -efficacy is "beliefs in one's capabilities to organize and execute the courses of action required to produce given attainments." In this context parents need a boost in self-efficacy as is advocated in studies. According to Bandura (2002), individuals with high self- efficacy in an area exert effort in that area and persevere regardless of constraints to achieve their intended targets. Thus, parents with high self -efficacy in ECD participation would respond with resilience in the face of adversity and never give up.

Lack of parental commitment was evident in their non- attendance at the meetings. The minute book revealed that very few parents attended parents meetings. To attest this, P3 claimed:

\begin{abstract}
...shame, Phi's wife shame called us to a meeting but I cannot spoil their project and intervene. I always tell Mamt... who is my neighbour and the one who guards my child when they are playing outside, that what they agreed in the meeting I am not against. Phi's wife started alone so why must we interfere with her work, she is good.
\end{abstract}

The statement above revealed that parents did not feel obliged to attend meetings as they did not claim ownership of activities in the centres

\title{
4. Discussion
}

The study's finding that some "parents" were grandparents is corroborated by Bridgemohan (2001). In this study, the actual parents (mothers) were claimed to have gone to nearby cities in search of employment and left their offsprings in the care of grandparents. As hinted above, parents took child support grant cards with them. The Child Support Grant is thus, used for purposes other than those it was designed for: to protect young children living in poverty (Viviers et al, 2013). This scenario calls for intervention from authorities responsible. Suggestions from respondents that children were sent to centres for food are an indication that the parents could not cope economically and hence needed support from other stakeholders, albeit the State/governments having provided grant funding.

Another finding was that parents sent their children to ECD centres so as to ensure freedom from the children. This may be contrary to what good child rearing practices suggest. Good parenting practices suggest that parents should ensure quality time with their children for psycho/emotional balance (Evans, 2006). It is important to note that if children are given proper care and support they will flourish physically, linguistically, cognitively, emotionally, socially and morally (Grover, 2005). That is why States/governments endeavour to provide a safe environment, good health, appropriate nutrition, stimulation, language development and above all interaction and attachment with caring adults.

Parents seemed to lack knowledge about the policies on ECD and its relationship with access to Grade one. P4 begrudgingly seemed to imply that the principal just created his/her policies as gatekeeping means and to deny children 
access to the "normal" school. It is however, stated in the government policies that children need to pass through Grade $\mathrm{R}$ before embarking on Grade 1 studies (Umalusi Centre for Education policy Development \& Wits Seminar Series, 2010).

Children were sent to ECD centres for security reasons. They would be guarded from perpetrators of rape. This reason for sending the children to ECD centres is very noble and enhances one of the South African national reasons for enrolling children into these centres as encapsulated in National Integrated Plan for Early Childhood Development in South Africa 2005-2010 (2005) and Viviers, Biersteker \& Moruane (2013) that ECD children go to places of safety. One wonders if these places are really safe. Investigative research may uncover differently.

Revelation by parents that they assist children by showing them how to hold pens and crayons indicates that they know that ECD children learn basics like that. It could however, reflect that the parents' illiteracy hinders them from more active participation in other areas, such as content. This does not reflect full participation in ECD as espoused in Mukuna \& Indoshi (2012) and Epstein (1995). From Indoshi \& Mukuna's perspective the parents in the sample are mainly concerned with home centred involvement rather than balance it with the school-centred one as they assist children with handling of writing tools at home and train them in doing household chores. In Epstein's (1995) view the parents should be involved in the six areas as highlighted in the introduction, namely; parenting, communication to and from school, volunteers, learning activities at home, decision-making and collaborating with the community. However, these parents can be positioned in parenting and to a less extent learning activities at home.

However, according to Peck (2014) educational involvement of families includes participating in activities that parents conduct at home and in early childhood settings to directly and indirectly support their children's learning. If this definition is anything to go by, these parents are participating on the home front and neglecting participating at the ECD settings.

Apart from illiteracy, the parents exuded lack of confidence. Parents such as P3 intimated that they would wait for duties to be delegated to them because they may be seen as too forward in a project that was started by the centre manager. This may portray that parents have low self -esteem because of their handcap; illiteracy. Parents need to be tutored in order to improve their self -efficacy. Bandura (1997:3) claims that self -efficacy is "beliefs in one's capabilities to organize and execute the courses of action required to produce given attainments." In this context parents need a boost in self-efficacy as is advocated in studies. According to Bandura (2002), individuals with high self- efficacy in an area exert effort in that area and persevere regardless of constraints to achieve their intended targets. Thus, parents with high self -efficacy in ECD participation would respond with resilience in the face of adversity and never give up.

Respondents revealed lack of knowledge on the role of ECD centres and their role as parents in ECD provisioning.. Moyo, Wadesango \& Kurebwa (2012) also contend that parents sometimes do not participate in ECD programmes due to lack of knowledge. They need to be assisted to imbibe the spirit of commitment in unison with the educators. Parents however, need to understand the tremendous impact they have on their children's lives. As Landers (1992: 3) put it, "Through their attention, expressed pleasure, listening and interest, the child's growing sense of self is nourished just as his or her body is nourished through food." Hence, parents need awareness in ECD provisioning.

\section{Conclusion}

Literature portrays the role of ECD centres and the benefits of parental participation in good stead. However, there seems to be a gap between rhetoric and reality; a gap between the vision and actual practice. Minimal parental participation was evident in the study. It is concluded from the findings that parents were not fully conversant of the roles of ECD centres and roles parents need to play in ECD centres for the benefit of learners. The reasons cited for this was mainly lack of knowledge due to illiteracy. What is needed is now is to move from concepts to actions as advocated by Albino \& Berry (2013).

\section{Recommendations}

The nature of the collaboration between sectors should be improved. For example, a multi- sectoral approach should be adopted in ECD provisioning monitoring and evaluation. For instance, Department of Social Development should take stock of the social grants to curb misuse and ensure it benefits the children and is used in the best interest of children.

Workshops for parents should be held to enhance their understanding of ECD programmes, the role of the centres and the type of participation the parents should be engaged in.

Adult literacy classes should be in place for parents of early childhood development learners to make them literate and in turn gainfully assist learners. 
School governing bodies SGBs should be introduced in these centres to maximise parental involvement.

Further research to investigate the implementation of ECD programmes viz a vis government policies on ECD provisioning.

\section{References}

Albino, N. \& Berry, L. (2013) Early Childhood Development Services in South Africa: What are the next steps? http://www.ci.org.zal depts./ci/pubs/pdf/general/guage2013EcdNextSteps.pdf

Babbie, E. \& Mouton, J. (2005). The Practice of Social Research. South African Edition. Cape Town: Oxford University Press.

Bandura, A. (1997). Self-efficacy: The Exercise of Control. New York: W.H. Freeman.

Bandura, A. (2002). Social Cognitive Theory in Cultural Context. Applied Psychology: An International Review. 51(2): 269-290.

Bowen, G.A. (2005). Preparing a QUALITATIVE Research- Based Dissertation: Lessons Learned. The Qualitative Report. 10(2):208-222.

Bowen, G.A. (2009). Analysis as Qualitative Research Method. Qualitative Research Journal. 9(2): 27-40.

Bridgemohan, R.R. (2001) Parent Involvement in Early Childhood Development in Kwazulu Natal. Unpublished Thesis submitted for Doctor of Education at the University of South Africa.

Bronfenbrenner, U. (1994). Ecological Models of Human Development. International Encyclopedia of Education. Volume 3 (2nd Edition). Oxford: Elsevier.

Brown, R. (ed). (1998). Knowledge, Education and Cultural Change. London: Tavistock.

Bryman, A. (2012). Social Research Methods. Oxford: Oxford University Press.

Deiner, P.L. (2010). Inclusive Early Childhood Education Development. Resources and Practice.Australia; Wadsworth.

Department of Education (1996). Interim Policy for ECD. Pretoria.

El Nokali, E., Bachman, H. J., \& Votrba-Drzal, E. (2010). Parent Involvement and Children's Academic and Social Development in Elementary School. Child Dev. 81(3): 988-1005.

Epstein, J. (1995). School/Family/Community partnerships: Caring for the Children we Share. Phi Delta Kappan. 76:701-712.

Epstein, J. (2001). School, Family and Community Partnerships: Preparing Educators and Improving Schools. Boulder, Co: Westview.

Evans, J.L. (2006). Parenting Programmes: An Important ECD Intervention Strategy. Paris: UNESCO.

Githinji, F.W. \& Kanga, A. (2011). Early Childhood Development Education in Kenya: A literature Review on Current Issues. International Journal of Current Research. 3(11):129-136.

Grover, D. (2005). The Young Child In The Family: Promoting Synergies Between Survival, Growth and Development in Early Childhood. Presentation at CARK MCH Forum. Dushambe, Tajikistan, September 20- 22, 2005.

Holloway, S. D., Yamamoto, Y., Suzuki, S. and Mindnich, J. D. (2008). Determinants of Parental Involvement in Early Schooling: Evidence from Japan. Early Childhood Research and Practice. 10(1):

Kibera, W. K. \& Kimokoti, A. (2007). Fundamentals of Sociology of Education with Reference to Africa. Nairobi: University of Nairobi Press.

Landers, C. (1992) Parent Education and Early Childhood Programmes. Coordinators' Notebook 12. The Consultative Group on Ealy Childhood Care and Development. Washington D.C: World Bank.

Maree, K. (2007). First Steps in Research. Pretoria.Van Schaik Publishers.

Moyo, J., Wadesango, N. \& Murebwa, M. (2012). Factors that Affect the Implemetation of Early Childhood Development Programmes in Zimbabwe. Stud Tribes Tribals. 10(2):141- 149.

Mukuna, T.E., and Indoshi, F.C. (2012). Parental Involvement and Perceptions of their Role in Early Childhood Development Education Pedagogy in Kenya. International Journal of Current Research. Vol 4(2): 265-274.

National Integrated Plan for Development in South Africa 2005- 2010 (2005). Pretoria.

Patton, M. Q. (2002). Qualitative Research and Evaluation Methods. (3rd Edition). Thousand Oaks: Sage Publications.

Peck, A. (2014). The Importance of Parent Involvement in Early Childhood Education. www.livestrong.com accessed 12/02/2014.

Ritchie, J. \& Lewis, J. (2003). Qualitative Research Practice. London: Sage Publications.

Schutt, R.K. (2012). Investigating the Social World: The Process of Practice of Research. (Seventh Edition) Boston: Sage Publications, Inc.

South African Children's Act (2006)

Stake, R. (1995). The Art of Case Research. Thousand Oaks. CA: Sage Publications.

Storbeck, C. \& Moodley, S. (2011). ECD Policies in South Africa- What about Children with Disabilities? Journal of African Studies and Development. 3(1):1-8.

Webster-Stratton, C. (1991). Strategies for Helping Families with Conduct Disordered Children. Journal of Child Psychology. 62(3): 583-593.

The Free Library (2006). Using a Multiple Case Study Design to Investigate the Information- Seeking Behaviour of Arts Administrators. http://www. The freelibrary.com/using+a+multiple-case+the...a01151440802. Accessed 14 June 2010.

Umalusi Centre for Education policy Development \& Wits Seminar Series (2010). Will Grade R Really Improve the Quality of South African Education?

Vargas- Baron, E. \& Schipper, J. (2012). Review of Policy and Planning Indicators in Early Childhood. The RISE Institute: UNESCO.

Viviers, A. Biersteker, L. \& Moruane, S. (2013). Strengthening ECD Service Delivery: Addressing Systemic Challenges. South African Child Guage. 2013:34-43.

Wall, K. (2011). Special Needs and Early Years: A Practitioner Guide. (3rd ed). London: Sage Publications Ltd.

Yin, R. K. (2011). Case Study Research: Design and Methods. Thousand Oaks: Sage Publications Inc. 